
de los países andinos con la Unión Europea.

\title{
¿POR QUÉ LOS ACUERDOS INTERNACIONALES DE INVERSIONES LIMITAN LOS PROCESOS DE TRANSFORMACIÓN PRODUCTIVA EN PAÍSES EN DESARROLLO? ALGUNAS RESPUESTAS DESDE LA EXPERIENCIA DE LOS PAÍSES ANDINOS CON LA UNIÓN EUROPEA
}

\section{WHY DO INTERNATIONAL INVESTMENT AGREEMENTS LIMIT THE PROCESS OF PRODUCTIVE TRANSFORMATION INSIDE DEVELOPING COUNTRIES? SOME ANSWERS FROM ANDEAN COUNTRIES EXPERIENCES WITH EUROPEAN UNION}

\author{
SANTIAGO GARCÍA ÁLVAREZ \\ Profesor de Economía \\ Universidad Central del Ecuador \\ santygarcial@yahoo.es
}

Fecha recepción: 12 de noviembre de 2010

Fecha aceptación: 10 de abril de 2011 doi: 10.5209/rev_PADE.2011.v22.7

\begin{abstract}
RESUMEN
Cuando se utilizan a los acuerdos internacionales de inversiones de tipo bilateral y regional, como principal mecanismo de atracción de inversiones hacia buena parte de los países en desarrollo, estos países están haciendo una apuesta equivocada, en la medida que tales acuerdos solo afectan al marco general de políticas y no a los determinantes económicos que son lo que finalmente pesan en la atracción de la IED, sin embargo, tal estrategia conlleva una serie de compromisos de protección irrestricta a las inversiones e implementación de políticas liberalizadoras. Todo este proceso reduce la capacidad de los estados de guiar a la IED hacia objetivos nacionales de desarrollo en general y de transformación productiva en particular.
\end{abstract}

PALABRAS CLAVES: Inversión extranjera directa, acuerdos internacionales de inversiones, transformación productiva, Comunidad Andina, Unión Europea.

JEL: F21, L16, O10, O14, O38

\begin{abstract}
When developing countries apply international investment agreements like a main way to attract FDI, they are betting incorrectly because such agreements are only able to affect the general framework of national politics, but not to the economic
\end{abstract}


García, Santiago. ¿Por qué los acuerdos internacionales de inversiones limitan los procesos de transformación productiva en países en desarrollo? algunas respuestas desde la experiencia de los países andinos con la Unión Europea.

determinants that are finally those with preponderance to attract FDI. However, this kind of strategy includes several engagements to protect FDI and to implement liberalization policies. As a result, states losses ability to guide FDI to national objectives related to development en general and to productive transformation en particular way.

KEY WORDS: Foreign direct investment, international investment agreements, productive transformation, Andean Community, European Union.

\section{INTRODUCCIÓN}

La visión ortodoxa de tipo neoliberal parte del supuesto de que la apertura y la liberalización de las inversiones extranjeras directas son los requisitos fundamentales para garantizar un dinamismo en los flujos de recursos desde el exterior. Frente a este supuesto automatismo, que se preocupa más de la cantidad que la calidad de la inversión extranjera directa -IED-, varios cuestionamientos se han formulado para criticar este aserto, en la medida que si bien la liberalización se ha profundizado pero sus beneficios no han resultado tan evidentes como originalmente se suponía.

Bajo esta perspectiva ortodoxa, los acuerdos internacionales de inversiones, en adelante AlIS, en su diferentes niveles multilateral, regional y bilateral, se convirtieron en los instrumentos indispensables para imponer ciertos "estándares internacionales" a favor de los inversionistas, vinculados con la protección y seguridad de las inversiones y la liberalización de los movimientos del capital.

En tales circunstancias, resulta legítimo preguntarse en dónde han quedado las aspiraciones de buena parte de los países en desarrollo -PED- en cuanto a implementar procesos de transformación de sus limitadas estructuras productivas.

Precisamente, el interés del artículo radica en bajar el nivel de abstracción del análisis desde los grandes temas del desarrollo vinculados con las inversiones extranjeras, hacia aspectos más puntuales como la transformación productiva de los PED y sus vínculos no tanto con la cantidad sino con la calidad de la IED recibida, además tomando como referencia la experiencia de los países andinos agrupados en la Comunidad Andina, en adelante CAN, con los países de la Unión Europea, en adelante UE.

Los países en desarrollo mantienen características de singularidad de sus estructuras económicas y sectoriales heterogéneas y desarticuladas, presencia de subempleo e informalidad, y concentración y mal funcionamiento de los mercados, inequidad creciente en la estructura de la distribución de la renta, una inserción estática y subordinada a la economía mundial y débiles marcos institucionales. En este contexto es donde se deben poner a prueba la validez de los supuestos ortodoxos de los beneficios de la IED.

De tal forma que el artículo tiene como objetivos a los siguientes: en primer lugar, evaluar las implicaciones que conllevan la negociación y la aplicación de AllS en el 
García, Santiago. ¿Por qué los acuerdos internacionales de inversiones limitan los procesos de transformación productiva en países en desarrollo? algunas respuestas desde la experiencia de los países andinos con la Unión Europea.

campo de las políticas conducentes a la transformación productiva al interior de los PED, y segundo, tomar como referencia de análisis el caso de cuatro países andinos en sus relaciones de inversiones con la Unión Europea.

La suposición que intentamos demostrar es que el costo de la suscripción de AlIS regionales y bilaterales para los PED es muy alto, debido a la pérdida de margen de maniobra (policy space) en la adopción de medidas de política económica interna dirigidas a la transformación productiva.

Para los fines de esta investigación, se define a la transformación productiva como el cambio estructural (industrialización) y el cambio en la especialización del tipo de comercio exterior basado en la explotación de recursos naturales hacia nuevas formas de inserción fundamentadas en bienes y servicios de mayor valor agregado, tal como se profundizará más adelante en los siguientes acápites. ${ }^{1}$

El trabajo consta de cuatro partes: una parte teórica que pasa revista a los principales aspectos de que están alrededor de los AlIS como uno más de los determinantes de la IED, las condiciones que se vinculan con los efectos esperados de la IED y los límites que pueden presentarse en materia de políticas económicas al firmar este tipo de acuerdos. La segunda aborda las características internas de los AlIS en sus diferentes niveles sean multilateral, regional y bilaterales. La tercera abarca el análisis de la experiencia de los países andinos en cuanto a la suscripción de AlIS bilaterales con países de la Unión Europea y una breve descripción del comportamiento de los flujos de inversiones directas recibidas. Finalmente, en la cuarta parte se presentan las principales conclusiones.

Ciertamente que este trabajo tiene como limitación que no pretende efectuar una evaluación a profundidad de la contribución de la IED proveniente de los países de la UE a los países andinos, sino más bien explorar las condiciones generales en las que dan tales flujos de inversiones.

\section{MARCO DE REFERENCIA: LA LIBERALIZACIÓN DE LA IED Y SUS LÍMITES PARA LA TRANSFORMACIÓN PRODUCTIVA}

\subsection{Los AllS como determinantes de la IED}

En el cuadro 1 se esquematiza el rol que cumplen los AllS en el marco de la promoción de la IED. Podemos apreciar los vínculos directos de los AlIS con el marco general de políticas, más no con los determinantes económicos de la IED, tampoco con los mecanismos financieros y no financieros de promoción. Pero al mismo tiempo conlleva un "sacrificio" muy marcado en términos de restricciones en el manejo de las políticas económicas internas.

\footnotetext{
${ }^{1}$ Esta forma de ver al cambio estructural se fundamenta en CEPAL (2008), organización que defiende la necesidad de generar y difundir el cambio técnico en los países latinoamericanos como uno los principales requisitos fundamentales para su desarrollo. Precisamente la industrialización y el cambio en el patrón de exportación hacia productos de mayor valor agregado vendrían a ser las expresiones concretas de tal cambio técnico. Los otros requisitos también necesarios pero que no se encuadran de manera efectiva en la presente investigación son: acumulación del capital humano, el fortalecimiento de las instituciones y la redistribución para la equidad social.
} 
García, Santiago. ¿Por qué los acuerdos internacionales de inversiones limitan los procesos de transformación productiva en países en desarrollo? algunas respuestas desde la experiencia de los países andinos con la Unión Europea.

\section{Cuadro 1}

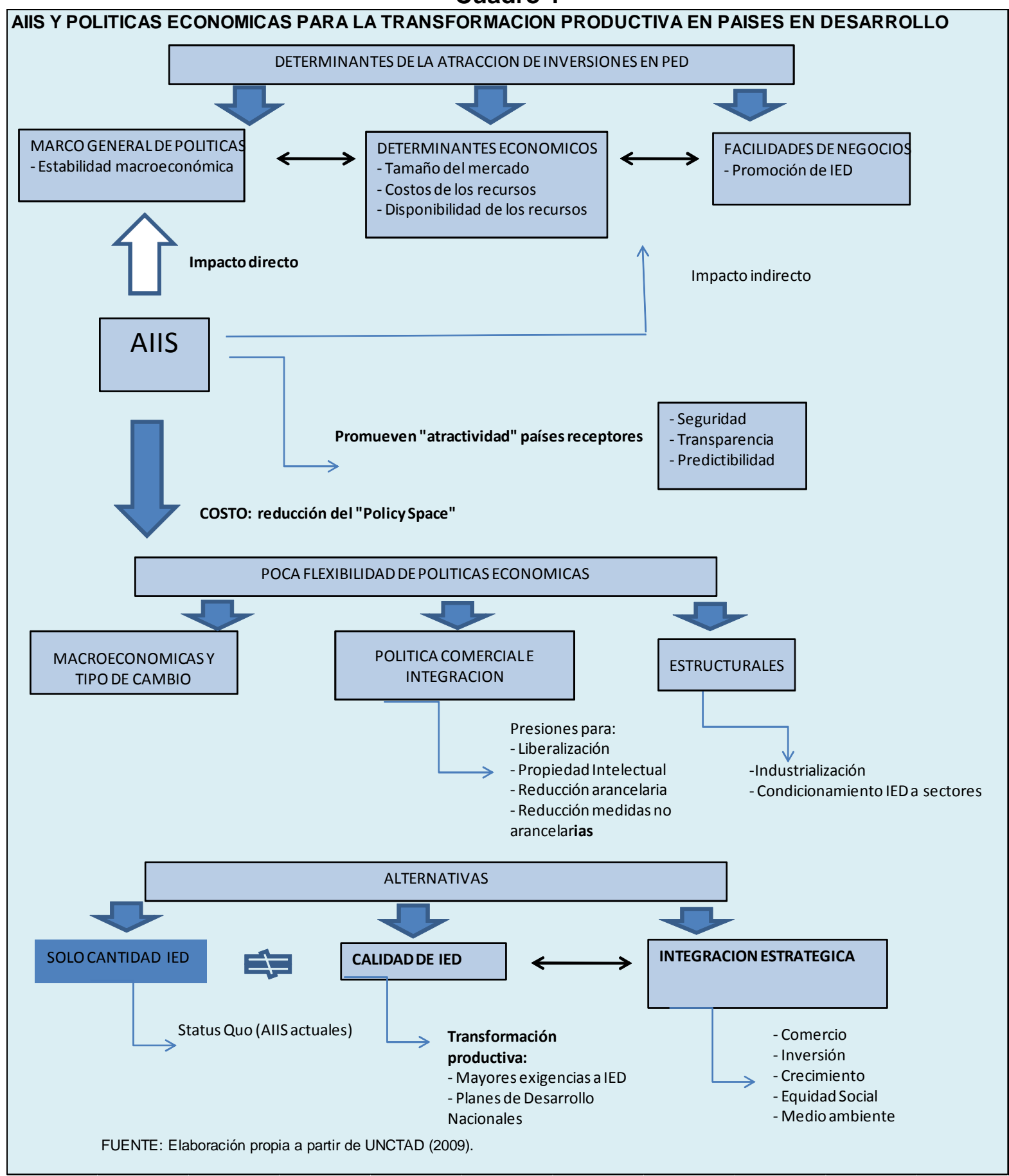

No resulta fácil distinguir los aspectos cualitativos que se dan en los procesos de internacionalización del capital productivo. En la práctica internacional, los PED han apostado por "mejorar" los factores de localización o de atracción (procesos de privatización, costos de mano de obra, tamaño de mercado, etc.) e implementar programas de promoción (beneficios fiscales, acceso a información, etc.), con la esperanza de que lleguen los capitales extranjeros con nuevos recursos, tecnología y conocimiento. 
García, Santiago. ¿Por qué los acuerdos internacionales de inversiones limitan los procesos de transformación productiva en países en desarrollo? algunas respuestas desde la experiencia de los países andinos con la Unión Europea.

La cuestión de fondo está que este proceso no es automático. La transferencia de las ventajas competitivas, que sin duda disponen las empresas transnacionales, está condicionada a su rentabilidad, a las exigencias mayores o menores que se presenten en los mercados internacionales, en definitiva a la estrategia empresarial de expansión.

Siguiendo los argumentos de la Conferencia de las Naciones Unidas sobre Comercio y Desarrollo (UNCTAD, 2009), los factores de localización en los PED receptores presentan tres dimensiones: (i) un marco general de políticas de tratamiento a la IED, (ii) los determinantes económicos propiamente dichos que incluyen tamaño del mercado, disponibilidad de recursos y costos absolutos y relativos de tales recursos; y, (iii) el régimen interno de promoción de la IED, incluidos los incentivos tributarios.

En tal contexto, para el tema que nos interesa, los AlIS influyen directamente en el primer elemento, es decir, en el marco general de tratamiento que un país receptor dispone para la IED, a la vez, mantienen una influencia indirecta en los dos elementos restantes.

Al respecto conviene señalar las reflexiones que hace la UNCTAD:

Los AllS son parte del marco de políticas para la IED y por lo tanto son uno de los muchos factores que impactan en las decisiones de dónde invertir por parte de las empresas inversoras. En consecuencia -este es uno de los principales mensajes de este estudio-, los AllS nunca pueden ser un instrumento de política suficiente para atraer la IED ${ }^{2}$ [Traducción propia del Autor]

De tal forma que la voz crítica de la UNCTAD deja claramente establecido que el impulso de los AIIS vienen a ser un camino corto e incompleto para atraer a la IED a los PED. Luego en los siguientes acápites veremos que con mayor detalle que esta estrategia va a conducir a una inevitable reducción de la capacidad de implementar políticas internas en estos países.

En la orilla opuesta, conviene que nos detengamos en los planteamientos de aquellas organizaciones internacionales que defiende a los AIIS como la estrategia indispensable para la atracción de inversiones, como son la Organización para la Cooperación y el Desarrollo Económico (OCDE) y el Banco Mundial.

En cuanto a los determinantes de la IED, los diferentes estudios y posiciones de la OCDE recalcan factores tales como: garantía de los derechos de propiedad, cumplimiento de contratos, existencia de competencia en los mercados, disponibilidad y uso libre de información, es decir, la promoción de un régimen liberal de tratamiento a la IED (OCDE, 2002).

Obviamente en este contexto liberal, los All'S deben servir tanto para la promoción de la IED como también para garantizar un trato no discriminatorio a favor de los inversores, o como jurídicamente se denomina cuidado de los derechos de los inversores.

\footnotetext{
${ }^{2}$ UNCTAD (2009), pág. xi.
} 
García, Santiago. ¿Por qué los acuerdos internacionales de inversiones limitan los procesos de transformación productiva en países en desarrollo? algunas respuestas desde la experiencia de los países andinos con la Unión Europea.

\subsection{Efectos de la IED: desarrollo y economías de escala}

Existe una amplia base de trabajos teóricos y empíricos relacionados con los efectos de la IED en el desarrollo de los PED receptores, aunque definitivamente no se han llegado a conclusiones definitivas, en una especie de "caja negra" que debe ser abierta tal como lo plantean Olivié, Pérez y Macías (2010).

De manera muy sintética podemos decir que se contraponen dos posiciones teóricas con respecto a los beneficios de la IED en el desarrollo de los países receptores, de un lado, la visión de que este proceso es de cierta manera unívoco y automático, según lo defienden autores como Dunning (1979 y 2003) o Rugman (1999). De otro lado, varios autores que consideran que se trata de un proceso dispar, contradictorio y que suele estar matizado por un conjunto de factores ya sean institucionales, de políticas, de estructura económica del país receptor, etc. Estos son los argumentos por ejemplo de Agosín (2010) y UNCTAD (1999 y 2003).

En el marco de las teorías microeconómicas, Dunning (1979 y 2003) plantea que existen tres condiciones que explican los movimientos de los capitales internacionales, primero, que las empresas que van invertir en el exterior disponen de una ventaja de propiedad en comparación con empresas de otras nacionalidades; segundo, que las empresas que actúan como inversionistas tienen la capacidad para sacar provecho de su posición internacional; y, tercero, la empresa decide expandir sus actividades en función de una serie de factores de localización presentes en el país receptor de la inversión y que le resultan atractivos $^{3}$.

Los supuestos del "paradigma OLI" han sido defendidos y promovidos por la teoría ortodoxa, la cual siempre ha estado interesada en mostrar las virtudes que conlleva la recepción de capitales extranjeros que traen conocimiento y tecnología, además de financiamiento, y la necesidad de poner a punto los factores de localización interna para que el todo el proceso empate y funcione.

La crítica surge porque no es verdad que las empresas inversoras transfieran automáticamente sus ventajas competitivas a los países en los que invierten, sino más bien todo va a depender de las condiciones que impongan los mercados en el exterior y de las exigencias que puedan imponer los PED receptores.

En cuanto a los efectos de economías de escala provocados por la presencia de IED, Lesher y Miroudot (2008) argumentan que éstas implican incrementos de la productividad en la economía receptora por la transferencia de conocimientos y por la puesta en juego de nuevos recursos de financiamiento externo.

Cuando el capital transnacional con fines productivos llega a un mercado receptor, trae consigo recursos financieros, humanos, tecnológicos, de conocimiento, de vínculos externos, entre otros. Luego, estos recursos crean una serie de

\footnotetext{
${ }^{3}$ A este enfoque conceptual se le conoce como el "paradigma OLI", "O" en referencia a las ventajas de propiedad, "I" a las ventajas de internacionalización y "L" a las ventajas de localización, según las letras iniciales en inglés.
} 
García, Santiago. ¿Por qué los acuerdos internacionales de inversiones limitan los procesos de transformación productiva en países en desarrollo? algunas respuestas desde la experiencia de los países andinos con la Unión Europea.

mecanismos o canales que van a provocar beneficios, directos e indirectos, con el aparato productivo del país receptor, tales como: mayor producción, acceso a tecnologías, capacitación de recursos humanos en empresas locales, aprendizaje empresarial, etc.

Sin embargo, las interconexiones anteriormente referidas no son de aplicación universal, sino que consideramos que van a depender de tres situaciones. En primer lugar, del tipo de modalidad de IED ${ }^{4}$; en segundo lugar, de las características estructurales y de desempeño de las economías receptoras, y, en tercer lugar, de las propias políticas económicas de los países receptores.

Los efectos de la IED van a tener relación directa con la estrategia -productiva, comercial, tecnológica- seguida por la empresa foránea y de la malla de relaciones que establece con las empresas domésticas -proveedoras y competidoras- y con los respectivos estados nacionales. El impacto del capital foráneo en la estructura productiva dependerá del grado de integración de las subsidiarias en el tejido productivo nacional y de las relaciones de cooperación o competencia que desarrolle con las empresas locales, lo cual determinará la envergadura del efecto expulsión o del efecto de economías de escala.

Ahora bien, aun cuando se llegase a aceptar que el traslado de economías de escala por parte de la IED hacia las economías receptoras no sería un proceso automático e inequívoco, sino más bien condicionado por un conjunto de factores externos e internos, la situación para los PED seguiría siendo compleja en la medida que estos países deberían recrear condiciones para la canalización de las economías de escala en un marco de disyuntivas de políticas.

En efecto, sí las diferencias en términos de grado de apertura y de liberalización no responden a las expectativas de la IED, simplemente no ingresarán nuevos capitales. Si por el contrario, implementan reformas aperturistas podrían llegar a comprometer condiciones mínimas necesarias para objetivos más amplios de desarrollo interno.

En síntesis, la amplitud y características de las economías de escala provenientes de la IED van a variar según los siguientes aspectos: el sector económico donde lleguen, la magnitud de las diferencias tecnológicas y de recursos humanos existentes entre las empresas extranjeras y las nacionales, las condiciones de competencia que exista al interior del país receptor y del tipo de inserción hacia la economía mundial. Consecuentemente, un requisito que se desprende de todos estos factores es que se va a requerir la existencia de sendos planes de desarrollo en los países en desarrollo receptores de IED, en la perspectiva que tales planes les permita visualizar mejor costos y beneficios de la IED.

\footnotetext{
${ }^{4}$ Las modalidades que suelen reconocerse son: inversiones encaminadas a la explotación de recursos ("resource seeking", aprovechamiento de mercados ("market seeking"), inversiones sustentas en la eficiencia y la productividad ("efficiency seeking")
} 
García, Santiago. ¿Por qué los acuerdos internacionales de inversiones limitan los procesos de transformación productiva en países en desarrollo? algunas respuestas desde la experiencia de los países andinos con la Unión Europea.

\subsection{Implementación de políticas nacionales en el marco de los AlIS}

Si se acepta que no existe tal automatismo de los beneficios de la IED bajo la perspectiva ortodoxa, entonces, uno de los puntos centrales viene a ser la capacidad de manejo de políticas económicas de los PED receptores para condicionar la entrada y desempeño de la IED en sus economías. Esta posición ha sido el caballo de batalla de la UNCTAD (2003 y 2009), la cual ha mantenido una visión más amplia sobre este tema en comparación con la OCDE (2002 y 2005) y el Banco Mundial (2005). Un resumen de las posiciones que asumen estas tres instituciones se encuentra en el cuadro 2.

La UNCTAD reivindica que los países receptores deben preservar su capacidad de establecer políticas para el desarrollo, todo lo cual podría implicar la imposición de condiciones de desempeño de las IED. Las políticas de liberalización y apertura pueden ser útiles para atraer cantidad de recursos externos, pero no son suficientes para obtener "calidad" de tales recursos, así que deben surgir políticas activas que establezcan condiciones a la IED relacionadas con medidas tales como: transferencia de tecnologías en plazos adecuados, elevación de compras locales, aseguramiento de mayores reinversiones, protección a consumidores y medio ambiente, cumplimiento de prácticas competitivas, prevención de expulsión de empresas locales con capacidad productiva, entre otras.

La posición de la UNCTAD frente a los AllS es bastante crítica, especialmente regionales y bilaterales, en el sentido de que estos instrumentos suelen limitar considerablemente las opciones de políticas de los países en desarrollo, cuando asumen compromisos exclusivamente en la línea neoliberal de apertura y liberalización. Se considera que los instrumentos jurídicos deberían apuntar a un balance entre las contribuciones potenciales de la IED con la preservación de las capacidades de formular políticas nacionales para el desarrollo UNCTAD (2003).

En un trabajo relativamente reciente de la UNCTAD (2009), se plantea que el espacio de políticas debería ser en tres ámbitos: políticas macroeconómicas y de manejo de tipo de cambio; políticas comerciales y de integración, y, políticas estructurales. Las primeras relacionadas con la macroeconomía y las finanzas internacionales constituyen un tema amplio y especializado, cuyos alcances sobrepasan a los objetivos de la investigación, mientras que sí se coincide en la importancia de los dos últimos aspectos, pero se los junta en una sola categoría, el cambio estructural.

Desde la perspectiva de la OCDE (2002 y 2005) y del Banco Mundial (2005), estas organizaciones internacionales manifiestan que la principal alternativa de política económica es aquella que se dirige a garantizar regímenes de apertura tanto hacia la entrada de capitales como al comercio exterior en general. La argumentación es que los regímenes abiertos atraen empresas competitivas, facilitan la adquisición de insumos y bienes de capital, en definitiva se aprovechan y/ o transfieren las ventajas comparativas. 
García, Santiago. ¿Por qué los acuerdos internacionales de inversiones limitan los procesos de transformación productiva en países en desarrollo? algunas respuestas desde la experiencia de los países andinos con la Unión Europea.

Cuadro 2

IED Y POLITICAS NACIONALES

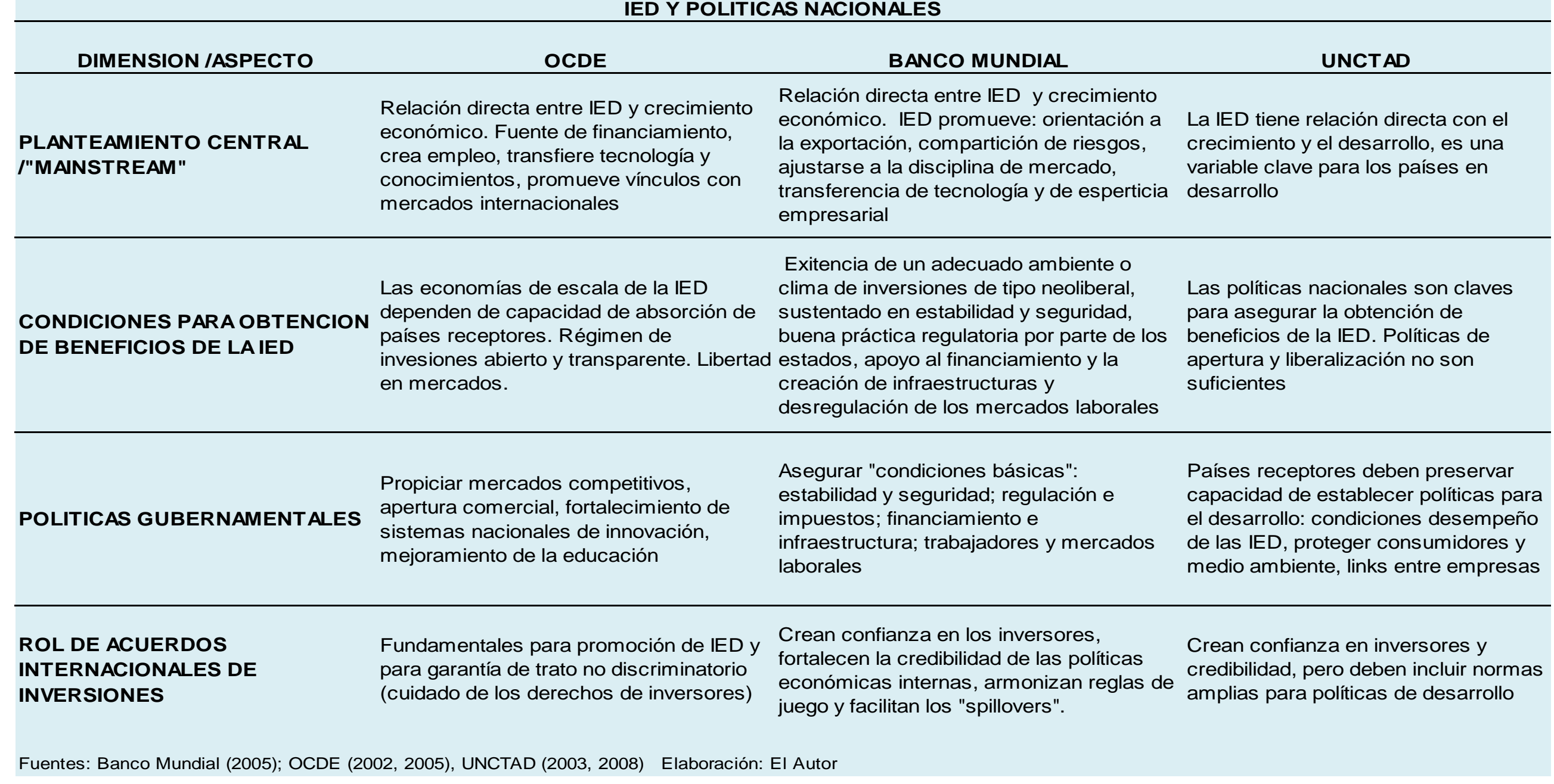


García, Santiago. ¿Por qué los acuerdos internacionales de inversiones limitan los procesos de transformación productiva en países en desarrollo? algunas respuestas desde la experiencia de los países andinos con la Unión Europea.

Conviene detenerse un poco más en la posición de la OCDE. Esta organización internacional considera que los efectos de la IED están en función de la capacidad de absorción de los países receptores. Esta es la versión liberal que se sustenta en el aprovechamiento de las ventajas comparativas, el acceso "universal" y sin trabas a las tecnologías y la eliminación de las intervenciones regulatorias del Estado. En todo caso, las políticas que subyacen a este tipo de planteamientos abogan por el funcionamiento de mercados competitivos sin intervenciones del Estado, la apertura comercial, el fortalecimiento de los sistemas nacionales de innovación, la mejora de los sistemas nacionales de educación.

De allí es comprensible que las políticas que están detrás de este enfoque promuevan aspectos tales como: garantía de los derechos de propiedad, cumplimiento de contratos, existencia de competencia en los mercados, disponibilidad y uso libre de información.

En cuanto al Banco Mundial, el Reporte del Desarrollo Mundial del 2005 establece que el clima de inversiones es el aspecto fundamental para el crecimiento y la reducción de la pobreza en países en desarrollo, si este clima o contexto socioeconómico es favorable se crean incentivos para las empresas que son las mayores responsables de generar empleo y riqueza, en caso contrario, se tendrían desincentivos que afectarían negativamente a las decisiones de inversión, sea de empresas locales o internacionales. Además, los beneficios de un adecuado clima de inversiones no solo favorecerían a las empresas sino a la totalidad de la sociedad en la medida que se inicia un proceso acumulativo de mayor inversión y de mayores oportunidades para la gente.

El Banco Mundial utiliza el término mejoramiento de los fundamentos o variables fundamentales para señalar los grandes propósitos del Estado para garantizar un favorable ambiente de negocios para el crecimiento y el desarrollo, además de la estabilidad política y macroeconómica antes referidas, se incluyen otros elementos como la transparencia y efectividad en la regulación y en la política impositiva, un mayor financiamiento a través de los mercados de capitales y crediticios, inversiones en infraestructura y desregulación de los mercados laborales. Ver cuadro 2

\section{SITUACIÓN ACTUAL Y PERSPECTIVAS DE LOS AIIS}

\subsection{Normativa internacional}

Como bien lo anota Ancos (2009), el tema es que los AllS siempre han privilegiado la norma por la protección contra la discriminación y para marcar el paso de procesos de apertura económica, pero han dejado de lado completamente otros objetivos también legítimos de cualquier Estado en relación al orden público o las políticas públicas.

En el marco de la OMC, existen dos acuerdos multilaterales que afectan a las inversiones: el Acuerdo sobre Medidas en Materia de Inversiones Relacionadas con el Comercio (AMIC) y el Acuerdo General sobre Comercio de Servicios (AGCS), 
García, Santiago. ¿Por qué los acuerdos internacionales de inversiones limitan los procesos de transformación productiva en países en desarrollo? algunas respuestas desde la experiencia de los países andinos con la Unión Europea.

ambos resultantes de la Ronda Uruguay en $1995 .^{5}$ En el presente caso, abordaremos el análisis del primero que tiene mayor relación con las políticas de transformación productiva.

EI AMIC determina un listado de medidas incompatibles con los principios que defiende la OMC y que los países miembros no pueden implementar y que básicamente se refieren a las posibilidades de imponer requisitos de desempeño a la IED. De tal forma que los PED tienen limitaciones para implementar políticas de apoyo a industrias nacientes, que sea dicho de paso, este tipo de medidas fueron aplicadas en su debido momento por los países desarrollados y por varios países asiáticos.

Las medidas AMIC pueden ser clasificadas en función de las obligaciones que asumen los países miembros de la OMC, tanto para su aplicación interna (Trato Nacional) como su aplicación en frontera (restricciones cualitativas). En el grupo de las primeras constan las obligaciones de no exigir requisitos de contenido local o compra de materias primas nacionales.

\section{Cuadro 3}

Acuerdo sobre Medidas en Materia de Inversiones Relacionadas con el Comercio (AMIC): Medidas en materia de inversiones incompatibles con normativa de OMC

\begin{tabular}{|c|c|c|}
\hline Obligaciones & MIC incompatibles & Relaciones con la transformación productiva \\
\hline \multirow[t]{2}{*}{$\begin{array}{l}\text { Aplicación del Trato Nacional (Art. II del Gatt } \\
\text { que se aplican internamente) }\end{array}$} & $\begin{array}{l}\text { Exigencias de requisitos de contenido local: compra de } \\
\text { productos de origen nacional o fuente nacional }\end{array}$ & $\begin{array}{l}\text { Requerimientos de contenido local apoyan la } \\
\text { articulación productiva entre IED y empresas } \\
\text { locales }\end{array}$ \\
\hline & $\begin{array}{l}\text { Exigencias de compras de productos importados } \\
\text { relacionadas con el volumen o el valor de las } \\
\text { exportaciones }\end{array}$ & $\begin{array}{l}\text { Requerimientos para un balance comercial se } \\
\text { relacionan con la necesidad de incrementar el } \\
\text { comercio internacional de doble vía }\end{array}$ \\
\hline \multirow[t]{4}{*}{$\begin{array}{l}\text { Eliminación de restricciones cualitativas } \\
\text { (Art. XI del Gatt que se aplican en frontera) }\end{array}$} & $\begin{array}{l}\text { Exigencias de importación de productos utilizados para } \\
\text { la producción local }\end{array}$ & $\begin{array}{l}\text { Restricciones de importaciones que podrían ser } \\
\text { proveídas por la producción local }\end{array}$ \\
\hline & $\begin{array}{l}\text { Exigencias de importación de productos relacionados } \\
\text { con el valor o volumen de producción local que luego se } \\
\text { exporte }\end{array}$ & $\begin{array}{l}\text { Requerimientos para un balance comercial se } \\
\text { relacionan con la necesidad de incrementar el } \\
\text { comercio internacional de doble vía }\end{array}$ \\
\hline & $\begin{array}{l}\text { Limitaciones al acceso a divisas para importar en } \\
\text { relación con las entradas de divisas atribuibles a esa } \\
\text { empresa importadora }\end{array}$ & $\begin{array}{l}\text { Requerimientos para un balance en el mercado } \\
\text { de divisas que impida la implementación de } \\
\text { ajustes monetarios }\end{array}$ \\
\hline & $\begin{array}{l}\text { Exigencias de exportación en términos de productos } \\
\text { terminados, de volumen o de valor o como proporción } \\
\text { del volumen o valor de su producción local }\end{array}$ & $\begin{array}{l}\text { Requerimientos de ventas domésticas ligadas a } \\
\text { las exportaciones, conducentes a incrementar los } \\
\text { encadenamientos productivos }\end{array}$ \\
\hline
\end{tabular}

En cuanto al segundo grupo de medidas relacionadas con la aplicación de restricciones cualitativas relacionadas con el comercio exterior, no son aplicables

\footnotetext{
${ }^{5}$ Existen otros acuerdos que tratan algunos aspectos de inversión tales como: el Acuerdo sobre los Aspectos de los Derechos de Propiedad Intelectual relacionados al Comercio (ADPIC), el Acuerdo sobre Subvenciones y Medidas Compensatorias y el Acuerdo sobre Contratación Pública, sin embargo su vinculación es indirecta por lo que no han sido abordados a profundidad en este estudio. 
García, Santiago. ¿Por qué los acuerdos internacionales de inversiones limitan los procesos de transformación productiva en países en desarrollo? algunas respuestas desde la experiencia de los países andinos con la Unión Europea.

las exigencias de importación de productos utilizados para la producción local, tampoco las exigencias de importación de productos relacionados con el valor o volumen de producción local que luego se exporte. No es posible imponer limitaciones al acceso a divisas para importar en relación con las entradas de divisas atribuibles a esa empresa importadora ni establecer exigencias de exportación bajo ninguna modalidad.

En el cuadro 3 se detallan las medidas AMIC que resultan incompatibles según la normativa de la OMC y algunas de implicaciones en materia de transformación productiva.

Ahora bien, del análisis de políticas que ha realizado la UNCTAD en materia de medidas tipo AMIC, se concluye que los grandes objetivos de industrialización y creación de mayor valor agregado en las economías en desarrollo no pueden descansar exclusivamente en este tipo de medidas, por lo que lo más importante es la cuestión de políticas nacionales dirigidas a fortalecer la capacidad productiva y la competitividad de las industrias locales, a través de programas de innovación tecnológica, capacitación de los recursos humanos, fortalecimiento de clústeres e incremento de la diversificación de mercados. ${ }^{6}$

\subsection{Tratados regionales de inversión}

Los acuerdos de integración suelen fundamentarse en los principios generales del AMIC, para luego establecer una serie de disposiciones destinadas a regular varios temas tales como: establecimiento de los inversionistas, propiedad intelectual y comercio de servicios.

Por ejemplo, el Tratado de Libre Comercio de América del Norte (TLCAN) estipula un conjunto de normas específicas para las inversiones. Así, el Capítulo 11 contiene 39 artículos divididos en 2 secciones sobre inversión y solución de controversias, pero también existen otras disposiciones sobre aspectos vinculados a la inversión, tales como: servicios financieros en el Capítulo 14, competencia, monopolios y empresas del Estado en el Capítulo 15, y entrada temporal de personas en el Capítulo 16. Básicamente, el capítulo de inversiones articula tres principios: tratamiento nacional, nación más favorecida y un "mínimo estándar de trato". 7 La IED tiene acceso a todos los sectores, excepto aquellos expresamente reservados para el Estado o empresas nacionales, según lo establezca la ley.

No existen requisitos de pre-establecimiento, las partes pueden tener disposiciones especiales en sus leyes, requiriendo la residencia de los inversionistas, el establecimiento legal de la inversión, o el suministro de información de negocios confidencial, si lo requiere la autoridad pertinente, entre otros.

\footnotetext{
${ }^{6}$ UNCTAD (2007b). Elimination of TRIMS: the experience of selected developing countries, United Nations, New York

7 Según Ancos (2009), el "trato justo y equitativo" busca ofrecer el mejor de los tratamientos tanto a los inversores y las inversiones extranjeras, como a las inversiones de los países no Partes del mismo, ya sea aplicando en TN o el NMF, además este trato también se hace extensivo a las "actividades asociadas" a la inversión (organización, el control de la operación, el mantenimiento y la gestión de las empresas).
}

Papeles de Europa

22 (2011): 170-196 
García, Santiago. ¿Por qué los acuerdos internacionales de inversiones limitan los procesos de transformación productiva en países en desarrollo? algunas respuestas desde la experiencia de los países andinos con la Unión Europea.

Quedan prohibidos los requisitos de desempeño tanto hacia los inversionistas de las Partes como a terceros. ${ }^{8}$ Sí están permitidas las medidas que contengan requisitos de salud, medioambiente o seguridad, siempre que no se apliquen de manera discriminatoria.

Las transferencias de un inversor de una Parte hacia otra Parte están protegidas. Las expropiaciones están prohibidas excepto por razones de utilidad pública, no pueden ser discriminatorias y debe ofrecer una indemnización justa y equitativa. No existen condicionantes sociales ni de tipo ambiental, aunque se determina que no se permitiría el ingreso de IED que afecte la salud, la seguridad o los estándares medioambientales del país receptor.

\subsection{Acuerdos bilaterales de inversión -BITS}

Estos acuerdos son instrumentos jurídicos que complementan de manera operativa los esquemas de integración regional y subregional, sean zonas de libre comercio o uniones aduaneras, los convenios para evitar doble tributación y los acuerdos multilaterales que de una u otra forma se relacionan con las inversiones.

El objetivo central de los BITS es salvaguardar las inversiones realizadas en territorio de los países signatarios, en la perspectiva de establecer medidas sustantivas específicas de protección de derechos de los inversionistas, mucho más allá que las tradicionales medidas de la legislación internacional relacionadas con la protección contra expropiaciones.

En términos generales, los BIT's contienen al menos los siguientes aspectos: (i) definición bien amplia de inversiones que incluya cualquier derecho sobre un bien, material o inmaterial, (ii) términos y condiciones de acceso a los mercados, (iii) mecanismo para la solución de disputas, (iv) seguridades de compensación en casos de expropiación por razones de interés público y (v) seguridades de compensación en casos de medidas equivalentes a expropiación.

Las críticas han arreciado contra los BIT's por ser esquemas similares para todo tipo de países en desarrollo sin importar sus características particulares. Pero más allá de este aspecto, el principal cuestionamiento es que estos acuerdos debilitan la soberanía de los países en desarrollo firmantes pues reducen la flexibilidad para la adecuación de políticas relacionadas con las inversiones y establecen el mecanismo de solución de controversias a través de instancias de arbitraje internacional como el Centro Internacional de Arreglo de Diferencias relativas a Inversiones -CIADI-, que

8 Según el Artículo 1106 del TLCAN, no es posible exigir requisitos tales como: contingencias a la exportación basadas en un cierto nivel o porcentaje de bienes o servicios; exigencias en el nivel de contenido local; preferencias hacia proveedores o compras de bienes y servicios locales; condicionar las importaciones y el tipo de cambio a los niveles de exportación o entrada de reservas; contingentes de producción y venta dentro del territorio; requisitos de transferencia tecnológica o de propiedad intelectual; y la provisión de bienes y servicios limitada a un área o región. Paradójicamente, los PD presionan a la vigencia de normas de origen, las cuales contienen estipulaciones sobre contenido local pero en cuyo caso si son aceptadas en el ordenamiento multilateral.

Papeles de Europa

22 (2011): 170-196 
García, Santiago. ¿Por qué los acuerdos internacionales de inversiones limitan los procesos de transformación productiva en países en desarrollo? algunas respuestas desde la experiencia de los países andinos con la Unión Europea.

es un tribunal arbitral dependiente del Banco Mundial especializado en resolver controversias entre las partes firmantes de los tratados bilaterales. ${ }^{9}$

Otro elemento de crítica a los BITS es su falta de compromisos en temas protección de derechos sociales y medioambientales, a lo mucho se delinean grandes preámbulos y principios que posteriormente no tienen ningún tipo de aplicación en los textos mismos de estos acuerdos, por tanto, quedan en simples enunciados sin carácter vinculante para las partes. ${ }^{10}$

La UNCTAD se ha preocupado en los últimos años de monitorear el creciente número de BIT's en todo el mundo. Según esta organización, el número BITs se incrementaron dramáticamente durante la década de los 90 . En efecto, pasaron de 385 in 1989 a un total de 2.265 en 2003, involucrando a un total de 176 países. El número de tratados para evitar la doble tributación llegaron a 2.256 in 2002. Ver tabla 1.

Tabla 1

Acuerdos Bilaterales de Inversiones (BITS) y Acuerdos Doble Tributación (ADT)

\begin{tabular}{|r|r|r|r|r|}
\hline & \multicolumn{2}{|c|}{ Total por año } & \multicolumn{2}{c|}{ Total acumulado } \\
\cline { 2 - 5 } & BITs & DTTs & BITs & DTTs \\
\hline 1990 & 61 & 50 & 446 & 1.193 \\
\hline 1991 & 81 & 55 & 527 & 1.248 \\
\hline 1992 & 124 & 62 & 651 & 1.309 \\
\hline 1993 & 129 & 96 & 780 & 1.405 \\
\hline 1994 & 191 & 107 & 971 & 1.512 \\
\hline 1995 & 202 & 101 & 1.173 & 1.613 \\
\hline 1996 & 211 & 114 & 1.384 & 1.727 \\
\hline 1997 & 172 & 126 & 1.556 & 1.852 \\
\hline 1998 & 171 & 95 & 1.727 & 1.947 \\
\hline 1999 & 129 & 114 & 1.857 & 2.061 \\
\hline 2000 & 84 & 57 & 1.941 & 2.118 \\
\hline 2001 & 159 & 68 & 2.099 & 2.185 \\
\hline 2002 & 82 & 68 & 2.181 & 2.255 \\
\hline
\end{tabular}

Fuente: UNCTAD, BITs y DTT databases

9 EI CIADI nació con el Convenio Internacional sobre Arreglo de Diferencias Relativas a Inversiones entre Estados y Nacionales de otros Estados firmado en Washington en 1965 y que entró en vigencia en 1966.

10 Algunos países como Estados Unidos, Canadá y Australia han empezado a incluir las cuestiones laborales y de empleo en sus acuerdos bilaterales de inversión, en la medida que establecen disposiciones para el ingreso del personal cualificado al territorio de la otra parte para propósitos relacionados con la inversión. En materia laboral, un paso importante lo ha dado el Acuerdo entre Estados Unidos con Perú, en el que se incluyen la exigencia de que ambas partes apliquen en sus propias legislaciones los estándares de la Organización Internacional del Trabajo, además cualquier disputa en este campo, están sujetas a un procedimiento estado-estado obligatorio muy similar a los mecanismos de resolución de controversias comerciales. 
García, Santiago. ¿Por qué los acuerdos internacionales de inversiones limitan los procesos de transformación productiva en países en desarrollo? algunas respuestas desde la experiencia de los países andinos con la Unión Europea.

En suma, el balance en cuanto al contenido de los acuerdos bilaterales de inversión tanto para la promoción del desarrollo en los países en desarrollo receptores de IED, como en relación a los derechos sociales y medioambientales, no podría ser calificado como satisfactorio, sigue primando el enfoque ortodoxo de protección exclusiva de los inversionistas, restricciones a la aplicación de políticas pro desarrollo y los compromisos en temas sociales y ambientales no terminan de "cuajar" adecuadamente para los intereses de los países en desarrollo.

\subsection{Perspectivas generales de la evolución de los AlIS}

En el plano multilateral, la Declaración Ministerial de Doha se estructuró a dos niveles, un contenido de directrices relacionado con la liberalización del comercio y la atención a los países en desarrollo y un conjunto de disposiciones generales y específicas de negociación que pasaron a formar parte del Programa de Trabajo. En este último, se establecieron varias "velocidades" de negociación: inmediata, a mediano plazo y sin plazo. Precisamente, el tema de inversiones, conjuntamente con la política de competencia, la facilitación de comercio y la transparencia de compras gubernamentales, quedaron sin plazo de negociación.

Parte de las negociaciones se refieren a discutir sobre alternativas que superen los problemas encontrados en la aplicación de los acuerdos, tales como: Agricultura, Servicios y Propiedad Intelectual relacionada con el Comercio. De tal forma que en el nivel multilateral no existen perspectivas de cambios profundos en las diferentes dimensiones que directa e indirectamente afectan a la IED.

En los planos regional y bilateral, van tomando fuerza las estipulaciones relacionadas con lo social y medioambiental, aunque de una manera dispersa según la región en el mundo y, en lo esencial, todavía con muchos enunciados y reducidos compromisos efectivos. Tales avances se han dado en los acuerdos regionales que promueven la Unión Europea y el EFTA, así como en el ámbito bilateral con los acuerdos que impulsa Estados Unidos, Canadá, Japón, entre otros.

También son relevantes las Guías y Principios de la $\mathrm{OCDE}^{11}$ que incluyen los temas que involucran la responsabilidad social corporativa de las ETN sean grandes 0 pequeñas, la gobernanza corporativa empresarial, la capacitación y mejoramiento de los recursos humanos, estándares de prácticas anticorrupción y aspectos relacionados con la responsabilidad ambiental. ${ }^{12}$

Los temas de anticorrupción constituyen una innovación más reciente y aparecen en varios acuerdos de Estados Unidos y en el Acuerdo de Cooperación Cotonou entre la UE y África, Caribe y Pacífico. Lo que sí parece emerger de manera más precisa en los AIIS bilaterales es la inclusión de una serie de principios establecidos por la Organización Internacional de Trabajo en cuanto a: promoción en los puestos de empleo, igualdad de oportunidades, seguridad y condiciones en el trabajo, etc.

\footnotetext{
${ }^{11}$ Ver OCED (2006).

${ }^{12}$ Para una visión crítica sobre la responsabilidad social corporativa, se sugiere ver: Melé, D (2007)
}

Papeles de Europa 
García, Santiago. ¿Por qué los acuerdos internacionales de inversiones limitan los procesos de transformación productiva en países en desarrollo? algunas respuestas desde la experiencia de los países andinos con la Unión Europea.

\section{LA EXPERIENCIA DE LOS PAÍSES ANDINOS CON LA UNIÓN EUROPEA}

La estrategia europea en materia de inversiones con América Latina se ha centrado básicamente en la puesta en marcha de Acuerdos de Protección de Inversión (BITS), y, en ciertos casos, a través de los llamados acuerdos de asociación, concretamente con México y Chile. Estos dos acuerdos de asociación presentan tres pilares, el diálogo político, la cooperación y el comercial. Los textos jurídicos utilizan un lenguaje que convoca a la cooperación entre las dos partes en diferentes dimensiones económicas, sociales y políticas.

Las disposiciones relacionadas con la inversión establecen una serie de compromisos genéricos para establecer condiciones atractivas y estables para las inversiones recíprocas, ${ }^{13}$ en particular mecanismos de información; apoyos al desarrollo de un entorno jurídico favorable a la inversión; desarrollo de procedimientos administrativos simplificados y armonizados; y el desarrollo de mecanismos de inversión conjunta. Luego en materia de protección de inversiones vinculan el fortalecimiento de los BITS existentes o futuros.

De tal manera quedan dos conclusiones fundamentales: primera, los mecanismos bilaterales y regionales se refuerzan entre sí porque los acuerdos de asociación vinculan directamente a los BITS, y, segunda, la "apuesta" europea ha sido lograr la protección de sus inversiones y la garantía de que recibirán condiciones estables y previsibles, incluso la solución de diferencias entre inversionistas y Estados a través del CIADI.

\subsection{Las negociaciones de un Acuerdo de Asociación con los países andinos}

Las negociaciones de un Acuerdo de Asociación entre la Unión Europea y la Comunidad Andina se iniciaron en junio de 2007, con el objetivo de consolidar y desarrollar las relaciones políticas y económicas entre las dos regiones. ${ }^{14}$ En un principio, se tenía previsto una negociación "bloque a bloque" entre los cuatro países andinos, Bolivia, Colombia, Ecuador y Perú, con la Unión Europea, sin embargo, estas negociaciones se suspendieron en junio de 2008 por la falta de consensos sobre el enfoque y los alcances del componente de comercio, especialmente por la posición crítica de Bolivia, en aspectos relacionados con la propiedad intelectual, el tratamiento a la biodiversidad, entre otros. ${ }^{15}$

De los documentos que se han hecho públicos en materia de inversiones, se pueden mencionar una serie de aspectos demandados por los países andinos,

\footnotetext{
${ }^{13}$ A partir de estas disposiciones genéricas, México se comprometió en el 2001 a implementar a los Códigos de Liberalización y el Instrumento de Trato Nacional de la OCDE, es decir, profundizando la liberalización de las inversiones.

14 El antecedente previo que debe tomarse en cuenta es el Acuerdo de Diálogo Político y Cooperación entre ambas regiones firmado en el 2003

${ }^{15}$ En enero de 2009 se reiniciaron las negociaciones con la exclusión de Bolivia pero nuevamente Ecuador suspendió las negociaciones en julio de 2009 aduciendo problemas de falta voluntad política de la Unión Europea sobre los aranceles del banano. Posteriormente estas negociaciones continuaron exclusivamente entre dos países andinos, Colombia y Perú, con el objeto de poner en marcha un acuerdo comercial. Estas negociaciones terminaron formalmente en marzo de 2010.
} 
García, Santiago. ¿Por qué los acuerdos internacionales de inversiones limitan los procesos de transformación productiva en países en desarrollo? algunas respuestas desde la experiencia de los países andinos con la Unión Europea.

especialmente por parte ecuatoriana, que no han sido abordados y que en ningún caso constan en los acuerdos de asociación con México y con Chile.

Para empezar, se plateó que el acuerdo de asociación con los países andinos debía contener de manera expresa que las partes no alentarán la inversión extranjera directa mediante la reducción de las leyes y normas locales de salud y seguridad ambientales, laborales u ocupacionales, ni mediante la flexibilización de las normas - leyes laborales fundamentales orientadas a proteger y promover la diversidad cultural.

Con respecto al comercio de servicios que también se relacionan con las inversiones, se acepta la liberalización progresiva del establecimiento y el comercio de servicios y para la cooperación en el comercio electrónico, pero considerando la diferencia existente en el nivel de desarrollo de las Partes. Además se argumentaba que las disposiciones del acuerdo de asociación no deberán ser interpretadas como exigencias a la privatización de empresas públicas, o a la participación privada en activos o empresas públicas o en la gestión de sectores estratégicos. ${ }^{16}$

Otro aspecto es que cada parte conserva el derecho de ejercer sus competencias y de regular e introducir nuevas regulaciones para cumplir objetivos legítimos de política pública y atender sus particulares necesidades de regulación dadas las asimetrías existentes. No será posible que se le impida a una parte aplicar sus leyes y regulaciones en relación con la contratación, trabajo y seguridad social.

Tabla 2

Acuerdos Bilaterales de Inversiones -BITS- entre Países Andinos y Países Europeos

\begin{tabular}{|c|c|c|c|c|c|c|c|}
\hline \multicolumn{2}{|c|}{ BOLIVIA } & \multicolumn{2}{|c|}{ COLOMBIA } & \multicolumn{2}{|c|}{ ECUADOR } & \multicolumn{2}{|c|}{ PERU } \\
\hline Contraparte & $\begin{array}{l}\text { Fecha entrada } \\
\text { en vigor }\end{array}$ & Contraparte & \begin{tabular}{|c|}
$\begin{array}{c}\text { Fecha entrada } \\
\text { en vigor }\end{array}$ \\
\end{tabular} & Contraparte & $\begin{array}{c}\text { Fecha entrada } \\
\text { en vigor }\end{array}$ & Contraparte & $\begin{array}{l}\text { Fecha entrada } \\
\text { en vigor }\end{array}$ \\
\hline Austria & 01-jul-02 & & & Finlandia & 16-dic-01 & Finlandia & 14-jun-96 \\
\hline Luxemburgo & 10-jun-04 & & & & & Bélgica/Luxemburgo & - \\
\hline Dinamarca & 22-mar-97 & & & & & Dinamarca & 17-feb-95 \\
\hline France & 12-oct-96 & & & Francia & 10-jun-96 & Francia & 30-may-96 \\
\hline Alemania & 09-nov-90 & & & Alemania & $12-$ feb-99 & Alemania & $01-m a y-97$ \\
\hline Italia & $22-$ feb-92 & Italia & nd & Italia & 01-nov-05 & Italia & 18-oct-95 \\
\hline Holanda & 01-nov-94 & & & Holanda & 01-jul-01 & Holanda & $01-$ feb-96 \\
\hline España & nd & España & 22-nov-07 & España & 18-jun-97 & España & 17-feb-96 \\
\hline Suecia & 03-jul-92 & & & Suecia & 31-may-01 & Suecia & 01-ago-94 \\
\hline Suiza & 13-may-91 & Suiza & nd & Suiza & 09-nov-69 & Suiza & 23-nov-93 \\
\hline \multirow[t]{3}{*}{ Reino Unido } & 01-feb-90 & Reino Unido & nd & Reino Unido & 24-ago-95 & Reino Unido & $21-a b r-94$ \\
\hline & & & & & & \begin{tabular}{|l|} 
Noruega \\
\end{tabular} & 09-may-95 \\
\hline & 11 & & 4 & & 9 & & 12 \\
\hline
\end{tabular}

De otro lado, la base sobre la cual se esperaba construir el mencionado acuerdo regional se fundamentaba en los BITS vigentes entre varios países europeos y los países andinos. Según el registro que lleva la UNCTAD, Bolivia contabiliza 11 BITS con países europeos, Ecuador tiene 4, Colombia dispone de 9 y Perú tiene 12. Los acuerdos más antiguos se remontan al año 1969 cuando Ecuador firmó con Suiza y

\footnotetext{
${ }^{16}$ La nueva Constitución del Ecuador promulgada en el 2008 establece que los sectores estratégicos son: la energía en todas sus formas, las telecomunicaciones, los recursos naturales no renovables, el transporte y la refinación de hidrocarburos, la biodiversidad y el patrimonio genético, el espectro radioeléctrico, el agua, y los demás que determine la ley
}

Papeles de Europa 
García, Santiago. ¿Por qué los acuerdos internacionales de inversiones limitan los procesos de transformación productiva en países en desarrollo? algunas respuestas desde la experiencia de los países andinos con la Unión Europea.

cuando Bolivia firmó con Alemania y Suiza a inicios de los años 90 . El acuerdo más reciente fue el firmado por Bolivia con Luxemburgo en el 2004. En general, buena parte de los BITS se implementaron en los años 90, tal como puede apreciarse en la siguiente tabla.

En definitiva, las posiciones de Bolivia y Ecuador, que reivindican una posición más activa del Estado y rechazan la aplicación de los mecanismos de solución de controversias del CIADI, chocan con los estándares convencionales promovidos por la UE en materia de inversiones basados en el trato no discriminatorio absoluto y en la garantía a los derechos de los inversionistas.

\subsection{La inversión europea en los países andinos}

Desde el punto de vista de los intereses europeos, los flujos de IED han sido marginales hacia los países andinos, pues históricamente las inversiones se han dirigido principalmente hacia Estados Unidos y luego hacia los países latinoamericanos más grandes como Brasil y México, luego a economías como la chilena, venezolana y uruguaya.

En términos de "stock" de la IED total de la UE en el continente americano para el año 2008, casi las tres cuartas partes están ubicadas en Norte América y la diferencia en Latinoamérica, en este último caso, los países que más acumulan inversiones europeas fueron Brasil (7\%), México (3\%), Argentina (3\%) y Chile (1\%), con lo cual tampoco aparecen los países andinos con valores significativos. Ver tablas 3 y 4.

Desde el otro lado de los intereses, la IED europea es importante para los países andinos, en la medida que representó aproximadamente el $15 \%$ del flujo total acumulado en el período 2000-2008. Para tener una relación comparativa, los países del NAFTA dentro los cuales se destacan Estados Unidos como el principal inversor representaron el 19\% del mencionado total. En todo caso, el flujo de IED de los países de la UE-15 pasó de 3.757 millones de dólares en el 2000 a apenas 750 millones en el 2005 y luego se recuperó hasta alcanzar 2.399 millones de dólares en el 2008.

No fue posible obtener la desagregación de la IED europea por sectores económicos, pero esta información si está disponible para el total de los flujos recibidos por los países andinos desde todo el mundo en el período 2000-2008. Así, el $35 \%$ del acumulado se dirigió a minería y petróleo, el $16 \%$ a la industria manufacturera, $11 \%$ a transporte y comunicaciones, $7 \%$ a finanzas y $5 \%$ al comercio. Estas cifras dan una idea de que los países andinos básicamente atraen inversiones en el área extractiva-minera. 
García, Santiago. ¿Por qué los acuerdos internacionales de inversiones limitan los procesos de transformación productiva en países en desarrollo? algunas respuestas desde la experiencia de los países andinos con la Unión Europea.

\subsection{Niveles de industrialización en los países andinos}

Para una aproximación sobre el grado de industrialización de los países andinos se utilizaron tres dimensiones con sus respectivos indicadores, según se detalla en el anexo $1^{17}$.

Colombia es el país de mayor capacidad industrial del conjunto de países andinos, al tomar en cuenta su Valor Agregado Manufacturero per cápita resulta que es un poco más del doble que de Ecuador, cuatro veces en comparación con Bolivia y un equivalente a una quinta parte superior al de Perú. Esta situación refleja la realidad de un país con avances importantes en los procesos de desarrollo manufacturero en varios campos de las industrias de textiles, alimentos, metalmecánica, entre otras. Ver tabla 6.

Al comparar la capacidad manufacturera en el contexto latinoamericano, se puede apreciar como Ecuador y Bolivia prácticamente se han estancado en su desarrollo industrial, en la medida que representaron $0,8 \%$ y $0,3 \%$, respectivamente. Concomitantemente con el indicador señalado en el párrafo anterior, Colombia casi duplica su presencia en el desarrollo manufacturero de Latinoamérica al pasar de un porcentaje de $3,8 \%$ en el 2000 a $6,1 \%$ en el 2008. Por su parte Perú también incrementa su participación en el período señalado. Ver tabla 7.

En cuanto a la importancia del sector manufacturero en las economías de los andinos, se puede observar una situación preocupante por el cada vez menor peso relativo de la industria frente al resto de las actividades económicas. En el período de análisis, Ecuador pierde intensidad en su industrialización, tal como puede observarse en la tabla 8 , con 4 puntos porcentuales de disminución. El resto de países muestran una situación de estancamiento.

La mayor capacidad exportadora está en Perú medida a través de las exportaciones manufactureras per cápita, ya que dispone de 630 dólares per cápita, en comparación con 402 dólares de Colombia, 310 dólares de Ecuador y 134 dólares en Bolivia, año 2008. En términos generales, Perú ha logrado diversificar de manera positiva sus exportaciones manufactureras, especialmente basadas en recursos naturales. Ver tabla 9.

Los datos de exportaciones por niveles tecnológicos muestran una mejor posición de Colombia en comparación con sus socios andinos. Las exportaciones de media y alta tecnología colombianas representaron el $32 \%$ de sus ventas totales al mundo en el año 2008, mientras que Ecuador tiene un porcentaje del $19 \%$, Perú solo $7 \%$ y Bolivia 6\%.

\footnotetext{
${ }^{17}$ El enfoque utilizado en este acápite se basa en la metodología de cálculo de la competitividad industrial que utiliza la ONUDI en sus diferentes informes del Desarrollo Industrial. Puesto que el objetivo del presente estudio no es analizar a profundidad los niveles de competitividad industrial de los países andinos, se procedió a escoger las dimensiones más relevantes a juicio del investigador para dar una visión general de los avances y limitaciones de los procesos de industrialización de los países que conforman la Comunidad Andina. Las estadísticas utilizadas fueron obtenidas de la Base de Datos de la ONUDI
}

Papeles de Europa 
García, Santiago. ¿Por qué los acuerdos internacionales de inversiones limitan los procesos de transformación productiva en países en desarrollo? algunas respuestas desde la experiencia de los países andinos con la Unión Europea.

Tabla 3

Unión Europea *: Flujos de IED (outward flows) por regiones y países seleccionados de destino Millones de euros

\begin{tabular}{|c|c|c|c|c|c|c|c|c|}
\hline PAS / REGION & 2001 & 2002 & 2003 & 2004 & 2005 & 2006 & 2007 & 2008 \\
\hline America & 211.134 & 48.008 & 53.013 & 57.448 & 65.505 & 187.218 & 317.773 & 140.903 \\
\hline America del Norte & 164.496 & 4.102 & 56.772 & 13.237 & 48.392 & 135.811 & 198.658 & 129.277 \\
\hline Estados Unidos & 158.706 & 2.704 & 51.394 & 15.496 & 36.525 & 104.712 & 168.891 & 121.442 \\
\hline America Latina & 29.644 & 11.244 & 5.220 & 19.720 & 13.038 & 16.834 & 25.206 & 14.391 \\
\hline Argentina & 5.612 & 1.159 & $(1.455)$ & $(1.257)$ & 1.663 & 3.397 & 2.435 & 4.408 \\
\hline Brazil & 10.050 & $(1.367)$ & 2.135 & 5.709 & 8.435 & 5.416 & 14.332 & $(1.061)$ \\
\hline Chile & 3.048 & 1.564 & 1.643 & 1.987 & 889 & 990 & (92) & 1.178 \\
\hline Mexico & 4.825 & 6.608 & 2.000 & 10.756 & 2.601 & 1.748 & 6.532 & 5.667 \\
\hline Uruguay & 1.229 & 450 & 88 & 187 & 118 & $(147)$ & 562 & 229 \\
\hline Venezuela & 2.914 & $(183)$ & $(275)$ & 1.071 & 1.424 & 2.251 & $(975)$ & 2.239 \\
\hline
\end{tabular}

*/ EU25 2001-2003 y EU27 desde 2004

Fuente: EUROSTAT Elaboración: Santiago García Álvarez

Tabla 4

Unión Europea*: Stock de IED (outward stock) por regiones y países seleccionados de destino Millones de euros

\begin{tabular}{|c|c|c|c|c|c|c|c|c|c|}
\hline PAS / REGION & 2001 & 2002 & 2003 & 2004 & 2005 & 2006 & 2007 & 2008 & $\begin{array}{l}\% \text { DEL TOTAL } \\
\text { AMERICA } 2008\end{array}$ \\
\hline America & 1.277 .076 & 1.065 .934 & 1.123 .384 & 1.144 .445 & 1.349 .767 & 1.495 .319 & 1.661 .524 & 1.701 .189 & \\
\hline America del Norte & 1.000 .607 & 843.194 & 828.890 & 806.469 & 938.759 & 1.064 .010 & 1.133 .894 & 1.198 .155 & 70 \\
\hline Estados Unidos & 915.251 & 760.153 & 747.548 & 731.757 & 844.627 & 949.257 & 992.412 & 1.058 .052 & 62 \\
\hline America Latina & 195.158 & 126.379 & 173.916 & 189.822 & 210.262 & 225.588 & 260.599 & 276.681 & 16 \\
\hline Argentina & 51.769 & 22.302 & 35.675 & 30.519 & 37.951 & 39.984 & 39.671 & 44.103 & 3 \\
\hline Brazil & 73.492 & 44.369 & 59.214 & 70.451 & 74.061 & 92.381 & 114.358 & 112.520 & 7 \\
\hline Chile & 15.396 & 12.541 & 15.494 & 16.332 & 18.227 & 13.764 & 13.311 & 12.324 & 1 \\
\hline Mexico & 28.237 & 27.638 & 29.614 & 38.853 & 42.505 & 45.122 & 48.669 & 49.048 & 3 \\
\hline Uruguay & 2.253 & 1.677 & 2.075 & 2.055 & 3.363 & 4.131 & 4.035 & 4.945 & 0 \\
\hline Venezuela & 9.427 & 6.817 & 5.215 & 5.514 & 9.370 & 10.210 & 12.360 & 15.293 & 1 \\
\hline
\end{tabular}

* EU25 2001-2003 y EU27 desde 2004

Fuente: EUROSTAT Elaboración: Santiago García Álvarez 
García, Santiago. ¿Por qué los acuerdos internacionales de inversiones limitan los procesos de transformación productiva en países en desarrollo? algunas respuestas desde la experiencia de los países andinos con la Unión Europea.

Tabla 5

COMUNIDAD ANDINA:FLUJO DE LAINVERSION EXTRANJERADIRECTAPOR REGIONES DE ORIGEN

(Millones de dólares)

\begin{tabular}{|c|c|c|c|c|c|c|c|c|c|c|c|}
\hline REGIONES & 2000 & 2001 & 2002 & 2003 & 2004 & 2005 & 2006 & 2007 & 2008 & $\begin{array}{l}\text { Acumulado } \\
2000-2008\end{array}$ & $\%$ del total \\
\hline TOTAL & 4.056 & 5.028 & 6.072 & 4.434 & 6.054 & 13.801 & 10.925 & 15.679 & 17.667 & 83.715 & \\
\hline NAFTA & 1.341 & 831 & 1.577 & 511 & 1.577 & 3.330 & 2.031 & 2.142 & 2.939 & 16.279 & 19,4 \\
\hline COMUNDAD ANDNA & 59 & 163 & 195 & .15 & .50 & 474 & 345 & 147 & 139 & 1.457 & 1,7 \\
\hline MERCOSUR & 140 & 188 & 232 & 102 & 245 & 644 & 626 & 832 & 478 & 3.487 & 4,2 \\
\hline AMERICACENTRAL & 301 & 199 & 236 & 496 & 188 & 210 & 338 & 614 & 864 & 3.446 & 4,1 \\
\hline UNONEUROPEA(UE-15) & 3.757 & 1.690 & 848 & 706 & 426 & 750 & 1.332 & 436 & 2.399 & 12.345 & 14,7 \\
\hline RESTO DE EUROPA & 502 & 244 & .12 & 182 & 80 & 3.799 & 211 & 106 & 289 & 5.408 & 6,5 \\
\hline ASIA & 48 & 35 & 44 & 90 & 21 & 114 & 44 & 130 & 152 & 679 & 0,8 \\
\hline
\end{tabular}

FUENTE: Banco Centrales de los Paises.

ELABORACION:Comunidad Andina-Secretaría General. Proveccio Estadísicica

Tabla 6

CAPACIDAD PRODUCTIVA: VALOR AGREGADO MANUFACTURERO (Vam) PERCAPITA MLLLONES DE DOLARES CORRIENTES Y MILLONES DE HABITANTES

\begin{tabular}{|l|r|r|r|r|r|r|r|r|r|}
\hline \multicolumn{1}{|c|}{ PAISES } & VAm 2000 & VAm 2004 & VAm 2008 & POB 2000 & POB 2004 & POB 2008 & $\begin{array}{c}\text { VAm/POB } \\
00\end{array}$ & $\begin{array}{c}\text { VAm/POB } \\
04\end{array}$ & $\begin{array}{l}\text { VAm/POB } \\
08\end{array}$ \\
\hline Ecuador & 2.170 & 2.881 & 5.004 & 12,3 & 12,9 & 13,5 & 176,3 & 223,0 & 371,3 \\
\hline Colombia & 13.619 & 17.730 & 35.958 & 39,8 & 42,3 & 44,5 & 342,4 & 419,1 & 807,4 \\
\hline Peru & 7.696 & 10.364 & 18.694 & 26,0 & 27,9 & 28,4 & 295,6 & 371,8 & 659,0 \\
\hline Bolivia & 1.112 & 1.097 & 1.862 & 8,3 & 9,0 & 9,7 & 133,7 & 121,8 & 192,3 \\
\hline
\end{tabular}

Fuente: Elaboración propia en base a estadísticas de ONUDI - INDSTAT 
García, Santiago. ¿Por qué los acuerdos internacionales de inversiones limitan los procesos de transformación productiva en países en desarrollo? algunas respuestas desde la experiencia de los países andinos con la Unión Europea.

Tabla 7

CAPACIDAD PRODUCTIVA: PARTICIPACION EN EL VALOR AGREGADO MANUFACTURERO (Vam) DE LAREGION MLLONES DE DOLARES CORRIENTES Y PORCENTAJES DE PARTICIPACION

\begin{tabular}{|c|c|c|c|c|c|c|c|c|c|}
\hline PASES & VAm 2000 & VAm 2004 & VAm 2008 & $\begin{array}{c}\text { VAm } \\
\text { REGION } \\
2000 \\
\end{array}$ & \begin{tabular}{|c|} 
VAm \\
REGION \\
2004 \\
\end{tabular} & $\begin{array}{c}\text { VAm } \\
\text { RECION } \\
2008 \\
\end{array}$ & $\begin{array}{l}\text { VAmVAm } \\
\text { REGION OO }\end{array}$ & $\begin{array}{l}\text { VAmVAm } \\
\text { RECIONO4 }\end{array}$ & $\begin{array}{l}\text { VAmVAm } \\
\text { RECGON 08 }\end{array}$ \\
\hline Eccuador & 2.170 & 2.881 & 5.004 & 361.183 & 377.274 & 591.984 & $0,6 \%$ & $0,8 \%$ & $0,8 \%$ \\
\hline Colombia & 13.619 & 17.730 & 35.950 & 361.183 & 377.274 & 591.984 & $3,8 \%$ & $4,7 \%$ & $6,1 \%$ \\
\hline Peru & 7.696 & 10.364 & 18.694 & 361.183 & 377.274 & 591.984 & $2,1 \%$ & $2,7 \%$ & $3,2 \%$ \\
\hline Bolinia & 1.112 & 1.097 & 1.862 & 361.183 & 377.274 & 591.984 & $0,3 \%$ & $0,3 \%$ & $0,3 \%$ \\
\hline
\end{tabular}

Fuente: Elaboración propia en base a estadísicicas de ONDDI - NDSTAT

Tabla 8

INSTENSIDAD DE LAINDUSTRIALIZACION: PARTICIPACION DEL VALOR AGREGADO MANUFACTURERO (Vam) EN EL PIB MILLONES DE DOLARES CORRIENTES Y PORCENTAJES DE PARTICIPACION

\begin{tabular}{|l|r|r|r|r|r|r|r|r|r|}
\hline \multicolumn{1}{r|}{ PASES } & VAm 2000 & VAm 2004 & VAm 2008 & PIB 2000 & PIB 2004 & PIB 2008 & VAm/PIB 00 & VAm/PIB 04 & VAm/PIB 08 \\
\hline Ecuador & 2.170 & 2.881 & 5.004 & 15.934 & 32.642 & 54.686 & $13,6 \%$ & $8,8 \%$ & $9,2 \%$ \\
\hline Colombia & 13.619 & 17.730 & 35.958 & 94.053 & 113.774 & 242.608 & $14,5 \%$ & $15,6 \%$ & $14,8 \%$ \\
\hline Peru & 7.696 & 10.364 & 18.694 & 53.336 & 69.701 & 128.933 & $14,4 \%$ & $14,9 \%$ & $14,5 \%$ \\
\hline Bolivia & 1.112 & 1.097 & 1.862 & 8.398 & 8.773 & 16.674 & $13,2 \%$ & $12,5 \%$ & $11,2 \%$ \\
\hline
\end{tabular}

Fuente: Elaboración propia en base a estadísticas de ONUDI - INDSTAT 
García, Santiago. ¿Por qué los acuerdos internacionales de inversiones limitan los procesos de transformación productiva en países en desarrollo? algunas respuestas desde la experiencia de los países andinos con la Unión Europea.

Tabla 9

CAPACIDAD EXPORTADORA: EXPORTACIONES MANUFACTURERAS (Xm) PER CAPITA MILES DE DOLARES CORRIENTES Y MILES DE HABIT ANTES

\begin{tabular}{|c|c|c|c|c|c|c|c|c|c|}
\hline PAISES & Xm 2000 & Xm 2004 & Xm 2008 & POB 2000 & POB 2004 & POB 2007 & Xi/POB 00 & Xi/POB 04 & Xi/POB 08 \\
\hline Ecuador & 898.589 & 1.545 .569 & 4.188.374 & 12.305 & 12.917 & 13.479 & 73,03 & 119,65 & 310,74 \\
\hline Colombia & 4.890 .843 & 9.135 .684 & 17.926.388 & 39781 & 42306 & 44.534 & 122,94 & 215,94 & 402,53 \\
\hline Peru & 4.146.016 & 7.823.721 & 18.177.498 & 26004 & 27.487 & 28.837 & 159,44 & 284,63 & 630,36 \\
\hline Bolivia & 681.813 & 725.335 & 1.295 .687 & 8317 & 9.009 & 9.684 & 81,98 & 80,51 & 133,80 \\
\hline
\end{tabular}

Tabla 10

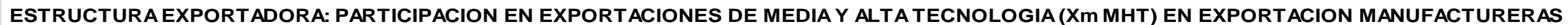
MILES DE DOLARES CORRIENTES Y PORCENTAJE DE PARTICIPACION

\begin{tabular}{|c|c|c|c|c|c|c|c|c|c|}
\hline PAISES & Xm MHT 2000 & Xm MHT 2004 & Xm MHT 2008 & $\mathrm{Xm} 2000$ & Xm 2004 & $\mathrm{Xm} 2008$ & XMHT/Xm 00 & \begin{tabular}{|l|}
$\mathrm{XMHT} / \mathrm{Xm} 04$ \\
\end{tabular} & XMHT/Xm 08 \\
\hline Ecuador & 174.542 & 238.117 & 810.492 & 898.589 & 1.545 .569 & 4.188 .374 & $19,4 \%$ & $15,4 \%$ & $19,4 \%$ \\
\hline Colombia & 2.070 .273 & 3.101 .928 & 5.674 .547 & 4.890 .843 & 9.135 .684 & 17.926.388 & $42,3 \%$ & $34,0 \%$ & $31,7 \%$ \\
\hline Peru & 196.203 & 336.049 & 1.210 .218 & 4.146.016 & 7.823.721 & 18.177.498 & $4,7 \%$ & $4,3 \%$ & $6,7 \%$ \\
\hline Bolivia & 212.813 & 79.338 & 79.424 & 681.813 & 725.335 & 1.295 .687 & $31,2 \%$ & $10,9 \%$ & $6,1 \%$ \\
\hline
\end{tabular}

Fuente: Elaboración propia en base a estadísticas de ONUDI - INDSTAT

\section{Tabla 11}

ESTRUCTURA EXPORTADORA: PARTICIPACION EN EXPORTACIONES DE MEDIA Y ALTA TECNOLOGIA(Xm MHT) MUNDIALES (W) MILES DE DOLARES CORRIENTES Y PORCENTAJE DE PARTICIPACION

\begin{tabular}{|c|c|c|c|c|c|c|c|c|c|}
\hline PASES & Xm MHT 2000 & Xm MHT 2004 & Xm MHT 2008 & XMHT W 2000 & XMHT W 2004 & XMHT W 2008 & \begin{tabular}{|c|} 
XMHT/XMHT \\
W 00 \\
\end{tabular} & \begin{tabular}{|c|}
$\begin{array}{c}\text { XMHT/XMHT } \\
\text { W } 04\end{array}$ \\
\end{tabular} & $\begin{array}{c}\text { XMHT/XMHTW } \\
08 \\
\end{array}$ \\
\hline Ecuador & 174.542 & 238.117 & 810.492 & 2.965 .853 .755 & 4.207 .960 .538 & 6.643.726.282 & $0,0 \%$ & $0,0 \%$ & $0,0 \%$ \\
\hline Colombia & 2.070 .273 & 3.101 .928 & 5.674 .547 & 2.965 .853 .755 & 4.207 .960 .538 & 6.643 .726 .282 & $0,1 \%$ & $0,1 \%$ & $0,1 \%$ \\
\hline Peru & 196.203 & 336.049 & 1.210 .218 & 2.965 .853 .755 & 4.207 .960 .538 & 6.643 .726 .282 & $0,0 \%$ & $0,0 \%$ & $0,0 \%$ \\
\hline Bolivia & 212.813 & 79.338 & 79.424 & 2.965 .853 .755 & 4.207 .960 .538 & 6.643.726.282 & $0,0 \%$ & $0,0 \%$ & $0,0 \%$ \\
\hline
\end{tabular}

Fuente: Elaboración propia en base a estadísticas de ONUDI - INDSTAT 
García, Santiago. ¿Por qué los acuerdos internacionales de inversiones limitan los procesos de transformación productiva en países en desarrollo? algunas respuestas desde la experiencia de los países andinos con la Unión Europea.

Bolivia es un caso especial ya que en el período de análisis su calidad de exportaciones tienen un bajón considerable, en la medida que la categoría de media y alta tecnología pasó de representar 31\% en el 2000 a apenas $6 \%$ en el 2008, entre otras razones, por el mayor peso que asumieron las exportaciones de gas (producto primario), lo cual modificó la estructura exportable boliviana.

El hecho concreto es que los cuatros países andinos reducen la participación de sus exportaciones de media y alta tecnología en las exportaciones totales.

Estos mismos indicadores de exportaciones manufactureras por nivel tecnológico medio y alto llevado al plano de las exportaciones mundiales, muestran únicamente a Colombia con una participación de $0,1 \%$ en este tipo de exportaciones, año 2008. Ver tablas 10 y 11.

\section{CONCLUSIONES}

En la medida que los factores económicos de localización (tamaño de los mercados, costos de los recursos, etc.) son lo que en realidad influyen enormemente en las decisiones de las empresas transnacionales, quedan cuestionadas las estrategias de los PED que confían la promoción de la IED a través de la firma de AlIS, pues estos acuerdos solo se relacionan con el marco general de tratamiento a las inversiones, que tienen su importancia pero no es el factor de mayor peso.

Por tanto, los PED se ubican en una estrategia equivocada cuando utilizan los AlIS como principal mecanismo de atracción de inversiones, pues estos instrumentos jurídicos conllevan una serie de compromisos de implementación de políticas que finalmente restringen la capacidad de los estados de guiar a la IED hacia objetivos nacionales de desarrollo en general y de cambio estructural en particular.

En lo concerniente a una posible visión alternativa al enfoque tradicional de los AlIS como instrumentos de promoción de inversiones, tal como lo afirma el Instituto Internacional para el Desarrollo Sostenible (IISD), se requiere una adecuada planificación para asegurar inversiones extranjeras de calidad, para lo cual se hace indispensable incluir más actores, cubrir más asuntos y equilibrar mejor los intereses de los principales actores en la inversión internacional: los inversores, los estados anfitriones y los estados locales. ${ }^{18}$

Este instituto está a favor de la aplicación de las exigencias de desempeño, que no terminan con el listado de medidas prohibidas del AMIC, sino que podrían extenderé a un conjunto de alternativas tales como: rendimiento de exportación; empresa mixta y participación en el capital social; investigación y desarrollo; transferencia de tecnología; empleo y capacitación; y otras exigencias tales como requerimientos de contenido local o el suministro de garantías en forma de bonos o de otro tipo. ${ }^{19}$

\footnotetext{
18 IISD (2005). ¿Una Agenda Sureña sobre Inversión? Fomento del desarrollo con derechos y obligaciones equilibrados para inversores, estados anfitriones y estados locales.

${ }^{19}$ EI IISD establece que es muy importante que las medidas de desempeño a la IED deben siempre estar definidas con claridad y mucho mejor si antes de hacerse efectivas las inversiones, a fin de que los inversionistas dispongan de la información necesaria para la toma de decisiones, luego la aplicación de las medidas deberán estar reguladas en el respectivo All. 
García, Santiago. ¿Por qué los acuerdos internacionales de inversiones limitan los procesos de transformación productiva en países en desarrollo? algunas respuestas desde la experiencia de los países andinos con la Unión Europea.

\section{BIBLIOGRAFÍA}

Agosín M. (2010): "Is Foreign Investment always Good for Development?" en Gallager, K and Chudnovsky, D. (ed.), Rethinking Foreign Investment for Sustainable Development: Lessons from Latin America, Am them Pr., EEUU, pp. 21-31

Ancos, H y Dámaso, J (2009): La promoción de la responsabilidad social en los tratados de inversión. Los casos de Bolivia y Venezuela, Fundación Carolina, Madrid.

Banco Mundial (2005): World Development Report. A Better Investment Climate for Everyone, World Bank y Oxford University Press.

CEPAL (2008): La Transformación Productiva. 20 años después. Viejos Problemas, Nuevas Oportunidades, Santiago de Chile.

DUNNING, J (1994): "Re-evaluating the benefits of foreign direct investment", Transnationa Corporations, vol. 3, no 1, febrero.

(1979): "Explaining changing patterns of international production: in defence of the eclectic theory", Oxford Bulletin of Economics and Statistics, volumen 41, pp 269-293.

Gligo, N. (2007): Políticas para atraer inversión extranjera directa en América Latina, Cepal, serie "Desarrollo Productivo", nำ 175, Santiago de Chile

Global Development and Environment Institute at Tufts University (2004): "Inversión Extranjera Directa y Desarrollo Sustentable. Lecciones desde las Américas, informe del Grupo de Trabajo sobre Desarrollo Sostenible y Medio Ambiente en las Américas". Disponible en: http:/www.ase.tufts.edu/gdae/

IISD (2005): ¿Una Agenda Sureña sobre Inversión? Fomento del desarrollo con derechos y obligaciones equilibrados para inversores, estados anfitriones y estados locales.

Lesher, M. y Miroudot, S. (2006): "Analysis of the Economic Impact of Investment Provisions in Regional Trade Agreements", OECD Trade Policy Working Papers, No. 36, OECD Publishing. doi:10.1787/322248021805

(2008): "FDI Spillovers and their Interrelationships with Trade", OECD Trade Policy Working Papers, No. 80, OECD publishing, (c) OECD. Doc: $10.1787 / 235843308250$

OCDE (2001): The OECD Guidelines for Multinational Enterprises: Text, Commentary and Clarifications, Organización para la Cooperación y el Desarrollo Económico, París

(2002): Foreign Direct Investment for Development: Maximising Benefits, Minimizing Costs, Paris

(2005): "Trade Policy: Promoting Investment for Development",OECD Trade Policy Working Paper No. 19, OECD, Paris.

(2006): Policy Framework for Investment, OECD, Paris.

Olivié, I, Pérez, A, y Macías, C (2010): La "caja negra" del impacto de la inversión directa en el desarrollo: propuesta de un marco teórico, Real Instituto Elcano, Documento de Trabajo /2010, 20/07/2010

ONUDI (2003): Informe sobre el Desarrollo Industrial 2002/2003, Viena

Paz, M.J. y Ramírez Cendrero, J.M. (2009): "Foreign direct investment and its contribution to economic development: determinants and limits" Ponencia presentada en el 6th International Conference Developments in Economic 
García, Santiago. ¿Por qué los acuerdos internacionales de inversiones limitan los procesos de transformación productiva en países en desarrollo? algunas respuestas desde la experiencia de los países andinos con la Unión Europea.

Theory and Policy, Departamento de Economía Aplicada V, Universidad del País Vasco, 2-3 de julio de 2009

Paz, M.J. (2002): "Los enfoques microeconómicos sobre la expansión de las empresas transnacionales", en Información Comercial Española. Boletín Económico, no 2732, Madrid, pp. 37-44

Rugman, A. (1999): "Forty years of the theory of the transnational corporation", Transnational Corporations, UNCTAD, vol. 8, nํㅡ 2, pp. 51-70.

UNCTAD (1999): FDI and the Challenge of Development. World Investment Report, Ginebra

(2002): World Investment Report 2002: Transnational Corporations and Export Competitiveness, New York and Geneva. United Nations. United Nations publication, Sales No. E.02.II.D.4.

(2003): World Investment Report: FDI Policies for Development: National and International Perspectives, New York and Geneva. United Nations. Publication, Sales No. E.03.II.D.8.

(2004a): World Investment Report 2004: The Shift Towards Services, New York and Geneva. United Nations. United Nations publication, Sales No. E.04.II.D.36.

(2004b): "Home Country Measures", Chapter 22 in International Investment Agreements: Key Issues, Volume III. New York and Geneva. United Nations. Publication, Sales No. E.05.II.D.6.

(2006): Investment Provisions in Economic Integration Agreements. New York and Geneva: United Nations. United Nations publication.

(2007a): World Investment Report 2007: Transnational Corporations, Extractive Industries and Development. New York and Geneva. United Nations. Publication Sales No. E.07.II.D.9.

(2007b): Elimination of TRIMS: The experience of selected developing countries.

(2007c): Bilateral Investment Treaties 1995-2006: Trends in Investment Rulemaking, New York and Geneva, United Nations publication, Sales No. E.06.II.D.16.

(2008a): "Recent developments in international investment agreements" (2007 -June 2008). IIA Monitor, No. 2 (UNCTAD/WEB/DIAE/IA/2008/1).

(2008b): World Investment Report 2008: Transnational Corporations and the Infrastructure Challenge, New York and Geneva, United Nations. Sales No. E.08.II.D.23.

(2008c): Investment Promotion Provisions in International Investment Agreements, UNCTAD Series on International Investment Policies for Development, New York and Geneva. United Nations. Sales No. E.08.II.D.5. (2009) "The Role of International Investment Agreements in Attracting Foreign Direct Investment to Developing Countries", Series on International Investment Policies for Development, Union Nation, New York y Geneva. 
García, Santiago. ¿Por qué los acuerdos internacionales de inversiones limitan los procesos de transformación productiva en países en desarrollo? algunas respuestas desde la experiencia de los países andinos con la Unión Europea.

\section{Anexo 1. DIMENSIONES E INDICADORES DE COMPETITIVIDAD INDUSTRIAL SEGÚN METODOLOGIA DE ONUDI}

> Capacidad productiva: (1) Medido por el Valor Agregado Manufacturero Per Cápita, que es un indicador básico de rendimiento industrial tomando en cuenta el tamaño de la economía y muestra la capacidad de un país para agregar valor en el proceso de industrialización. Otro indicador es (2) Participación en el Valor Agregado Manufacturero Total de la Región, que muestra el impacto productivo que tiene un país específico en la dinámica industrial de su región, en el presente caso, la región latinoamericana.

$>$ Intensidad del proceso de industrialización: Medido por (3) Participación del Valor Agregado Manufacturero en el PIB. Se trata de un indicador que refleja la importancia del sector manufacturero en la economía de un país

$>$ Capacidad exportadora manufacturera: Medido por (4) Exportaciones Manufactureras Per Cápita. Este indicador muestra la capacidad de un país de abastecer al mercado mundial.

$>$ Estructura exportadora: La calidad de las exportaciones de un país se mide a través de dos indicadores: (5) Participación de las exportaciones de mediana y alta tecnología en las exportaciones manufactureras de un país, y, (6) Participación de las Exportaciones de Mediana y Alta Tecnología de un país en las exportaciones manufactureras del mundo

FUENTE: Elaboración propia a partir de ONUDI (2003). Informe sobre el Desarrollo Industrial 2002/2003. Viena 